\title{
Analytical behavior of concrete-filled aluminum tubular stub columns under axial compression
}

\author{
H-Y. Zhao ${ }^{\text {a }}$, F-C. Wang ${ }^{\mathrm{a} *}$, L-H. Han ${ }^{\mathrm{a}}$ \\ aDepartment of Civil Engineering, Tsinghua University, Beijing, China \\ *corresponding author, e-mail address: wangfacheng@tsinghua.edu.cn
}

\begin{abstract}
This paper presents numerical investigation of circular concrete-filled aluminum tubular (CFAT) stub columns under axial compression. The numerical models were developed using the finite element (FE) package ABAQUS. The parameters commonly employed in conventional CFST FE modeling have been discussed in this study. The nonlinearities of concrete and aluminum materials and the interaction between concrete and aluminum tube were considered. Numerical models were validated against collected experimental data. The ultimate loads, load-axial strain relationship and failure modes from numerical simulations were compared with those from experiments. The verified FE model was used to analyze structural behavior of full histories of the corresponding load-deformation $N-\varepsilon$ response. Load-deformation $N-\varepsilon$ curves for both concrete and aluminum tube were also presented. Upon on validation of the FE models, additional structural performance data over a wide range of diameter-to-thickness ratios, aluminum grades and concrete strengths were generated for parametric studies. The influences of diameter-to-thickness ratios, aluminum grades and concrete strengths on the ultimate strength were presented in this paper.
\end{abstract}

Keywords: concrete-filled aluminum tubes (CFAT); circular hollow sections; stub columns, compressive behavior; finite element analysis.

\section{Introduction}

Aluminum alloy material has lower stiffness than carbon steel material since the Young's modulus of aluminum alloy material is lower than that of the carbon steel material. Filling aluminum tube columns with concrete is an alternative approach to increase the specimen ultimate strength.

Structural behaviors of CFAT stub columns under axial compressions have been investigated by researchers, such as Zhou and Young $[1,2]$. It was shown that aluminum tube columns filled with concrete could effectively take advantages of these two materials providing high cross-section compressive resistance with better anticorrosion ability. Local buckling effects of aluminum tubes have been improved due to the concrete infill. Chen et al. [3] and Feng et al. [4] have conducted experiments on concrete-filled aluminum alloy thin-walled tubes subjected to in-plane bending.
The ultimate strengths, failure modes, flexural stiffness, ductility and curves of test specimens were studied. Gardner and Ashraf [5] have proposed non-linear metallic material models. $\mathrm{Su}$ et al. [6] have investigated cross-section capacity of aluminum alloy in compression. Experimental behaviors of aluminum tube without concrete infill have been investigated by Zhu and Young [7]. It was shown that the local buckling, overall buckling and interaction of local and overall buckling were main failure modes of aluminum tube without concrete.

The purpose of this paper is to establish finite element (FE) models of CFAT stub columns under axial compression and investigate the structural behavior during the full history of loading. After being validated, the FE models were used to analysis the complete load-deformation $N-\varepsilon$ curves. Additional structural performance data over a wide range of diameter-to-thickness ratios, 
aluminum grades and concrete strengths were generated for parametric studies.

\section{Finite element model and verification}

A numerical modeling program using ABAQUS [8] has been performed to simulate the structural behaviors of the CFAT stub columns. The FE model consists of the aluminum tube, concrete infill and the interface between the aluminum tube and the concrete infill. Fig. 1 illustrates the cross section of one CFAT stub column, while $D$ and $t$ represent the diameter and thickness, respectively.

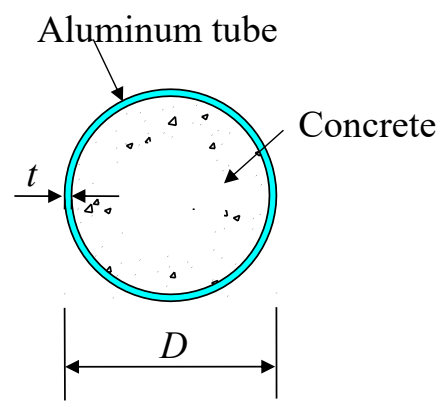

Fig. 1. Cross section of CFAT stub column.

\subsection{Element, boundary condition and method of loading}

The three-dimensional eight-node solid element (C3D8) was selected to model the concrete since the concrete infill can prevent the inward buckling of the aluminum tubes. The four-noded shell elements with reduced integration (S4R) was selected to model the aluminum tubes. The FE mesh sizes were investigated in order to achieve reliable modeling with reasonable computational time.

The axial compressive load was applied by specifying displacement at the top surface of CFAT stub columns, while the other degrees of freedom of CFAT stub columns were restricted.

\subsection{Aluminum tubes}

Zhou and Young [2,9] have measured and analyzed stress-strain curves for aluminum tubes. The reported stress-strain curves are applied for aluminum tubes in this study. The Young's modulus of aluminum are adopted by the measured value and the Poisson's ratio is defined as 0.3. In the analysis of the FE modeling of CFAT stub columns, the nominal static stress-strain curve of aluminum was converted to a true stress and plastic strain curve due to the large elastic strain.

\subsection{Concrete infill}

The uniaxial compressive strength and the corresponding strain of concrete have been enhanced due to lateral confining pressure. The damage plasticity model was utilized for concrete. The elastic modulus and Poisson's ratio of concrete were defined as $4730 \sqrt{f_{c}^{\prime}}[10]$ and 0.2 , respectively, and $f_{\mathrm{c}}$ ' represents the compressive strength of concrete cylinder. The core concrete model suggested by Han et al. $[11,12]$ was adopted in this study. For the FE model of CFAT stub columns in tension, fracture energy based approach developed by Hillerborg et al. [13] was adopted in this analysis.

\subsection{Modeling of aluminum tube-concrete infill interface}

Contact pair was used to model the interfaces between the aluminum tube and concrete. The "hard contact" model was used along the normal direction to the interface and "penalty" was used along the tangential direction. Friction coefficient of 0.25 was used in this study.

\subsection{Verification of finite element model}

The developed FE model using ABAQUS has been validated through comparisons between the predicted results and tests reported by Zhou and Young [2] on circular CFAT stub columns. The comparisons are presented in Table 1. CHS1-CHS10 denote ten series of CHS aluminum tubes filled with concrete (reported by [2]) and were employed in this study. The tubes were fabricated by extrusion using 6061-T6 heat-treated aluminum alloy. The nominal concrete cylinder strengths are 40 , 70 and $100 \mathrm{MPa}$. The nominal section sizes $(D \times t)$ of the series CHS1, CHS2, CHS3, CHS4, CHS5, CHS6, CHS7, CHS8, CHS9 and CHS10 are $38 \times 4,50 \times 3,60 \times 2.5,76 \times 2,100 \times 2,120 \times 2.5$, $150 \times 2.5,150 \times 5,160 \times 4$ and $180 \times 3.5 \mathrm{~mm}$, respectively.

Table 1 shows the comparison between the test results $\left(P_{\text {Exp }}\right)$ and the column strengths $\left(P_{\mathrm{FEA}}\right)$ from the FE model. The mean value of the $P_{\text {Exp }} / P_{\text {FEA }}$ ratio is 0.996 with the corresponding coefficient of variation $(\mathrm{COV})$ of 0.079 . The load-axial strain relationships of CFAT stub columns from tests and FE simulations were analyzed to validate the $\mathrm{FE}$ models. The comparisons of the load-axial strain relationships obtained from the 
experimental results (Exp) and the FE results (FEA) were shown in Fig. 2. The load values from FE simulations were consistently and slightly larger than those from experiments. This may be attributed to the fact that the concrete material models employed initially for CFST in which the concrete infill in axially loaded CFAT stub columns may behave in a manner with minor reduction on cross-section ultimate strength.

In addition, the failure modes of CFAT stub columns from FE simulations were verified against those from test results, as presented in Fig. 3. In general, for relatively slender sections, both local buckling of aluminum tubes and concrete crushing were observed. Good agreements have been achieved between the experimental results and FE results in terms of the ultimate loads, the load-axial strain relationship and the failure modes.

Table 1. Verification of finite element model.

\begin{tabular}{lllll}
\hline Specimen & $\begin{array}{l}\boldsymbol{D} / \boldsymbol{t} \\
\text { ratio }\end{array}$ & $\begin{array}{l}\boldsymbol{P}_{\text {Exp }} \\
/ \mathbf{k N}\end{array}$ & $\begin{array}{l}\boldsymbol{P}_{\text {FEA }} \\
/ \mathbf{k N}\end{array}$ & $\begin{array}{l}\boldsymbol{P}_{\text {Exp }} / \\
\boldsymbol{P}_{\text {FEA }}\end{array}$ \\
\hline CHS1-C0 & 9.70 & 114.5 & 107.8 & 1.062 \\
CHS1-C40 & 9.80 & 158.9 & 166.0 & 0.957 \\
CHS1-C70 & 9.70 & 167.2 & 169.6 & 0.986 \\
CHS1-C100 & 9.70 & 171.5 & 166.0 & 1.033 \\
CHS2-C0 & 16.0 & 141.2 & 139.8 & 1.010 \\
CHS2-C40 & 16.0 & 217.0 & 249.1 & 0.871 \\
CHS2-C70 & 16.0 & 238.9 & 262.6 & 0.910 \\
CHS2-C100 & 16.0 & 327.5 & 286.1 & 1.145 \\
CHS3-C0 & 23.8 & 121.3 & 118.4 & 1.024 \\
CHS3-C40 & 23.5 & 244.1 & 247.9 & 0.985 \\
CHS3-C70 & 23.6 & 292.4 & 296.7 & 0.986 \\
CHS3-C100 & 23.7 & 412.6 & 363.5 & 1.135 \\
CHS4-C0 & 37.1 & 113.4 & 114.5 & 0.990 \\
CHS4-C40 & 36.9 & 329.9 & 326.7 & 1.010 \\
CHS4-C70 & 36.9 & 415.7 & 418.9 & 0.992 \\
CHS4-C100 & 37.1 & 611.4 & 542.4 & 1.127 \\
CHS5-C0 & 49.5 & 162.7 & 150.7 & 1.080 \\
CHS5-C40 & 49.4 & 543.6 & 532.0 & 1.022 \\
CHS5-C70 & 48.4 & 712.0 & 701.4 & 1.015 \\
CHS5-C100 & 48.8 & 995.8 & 930.3 & 1.070 \\
CHS6-C0 & 46.9 & 264.5 & 235.6 & 1.123 \\
CHS6-C40 & 48.1 & 822.8 & 820.4 & 1.003 \\
CHS6-C70 & 47.1 & 1010 & 1075.0 & 0.940 \\
CHS6-C100 & 48.3 & 1389 & 1410.0 & 0.985 \\
CHS7-C0 & 59.7 & 283.9 & 293.8 & 0.966 \\
CHS7-C40 & 59.3 & 1111 & 1312.0 & 0.847 \\
CHS7-C70 & 59.1 & 1496 & 1749.0 & 0.855 \\
CHS7-C100 & 59.2 & 2058 & 2344.0 & 0.878 \\
CHS8-C0 & 30.1 & 525.8 & 501.3 & 1.049 \\
CHS8-C40 & 29.9 & 1482 & 1547.0 & 0.958 \\
CHS8-C70 & 29.8 & 1741 & 1906.0 & 0.913
\end{tabular}

\begin{tabular}{lllll} 
CHS8-C100 & 29.9 & 2666 & 2409.0 & 1.107 \\
CHS9-C0 & 40.0 & 456.1 & 425.9 & 1.071 \\
CHS9-C40 & 39.7 & 1494 & 1655.0 & 0.903 \\
CHS9-C70 & 39.4 & 1974 & 2123.0 & 0.930 \\
CHS9-C100 & 39.5 & 2797 & 2748.0 & 1.018 \\
CHS10-C0 & 48.1 & 482.8 & 550.0 & 0.878 \\
CHS10-C40 & 48.5 & 1690 & 1758.0 & 0.961 \\
CHS10-C70 & 48.9 & 2274 & 2283.0 & 0.996 \\
CHS10-C100 & 48.1 & 3139 & 2947.0 & 1.065 \\
Mean & & & & 0.996 \\
COV & & & & 0.079 \\
\hline
\end{tabular}

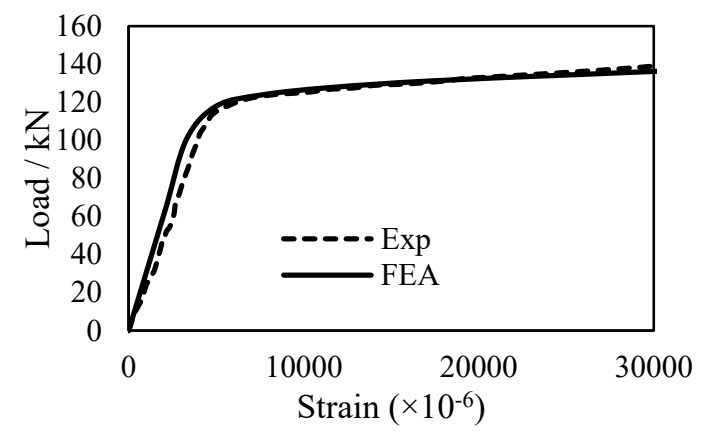

(a) CHS2-C0.

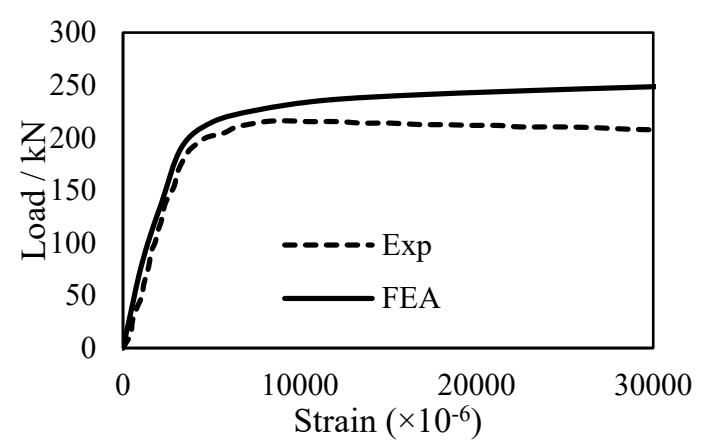

(b) CHS2-C40.

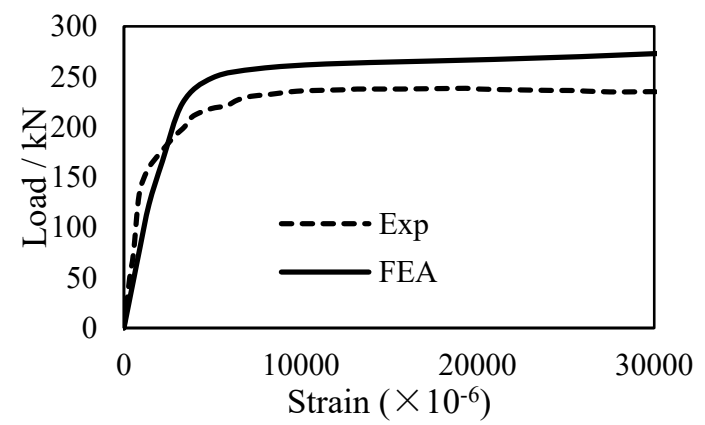

(c) CHS2-C70. 


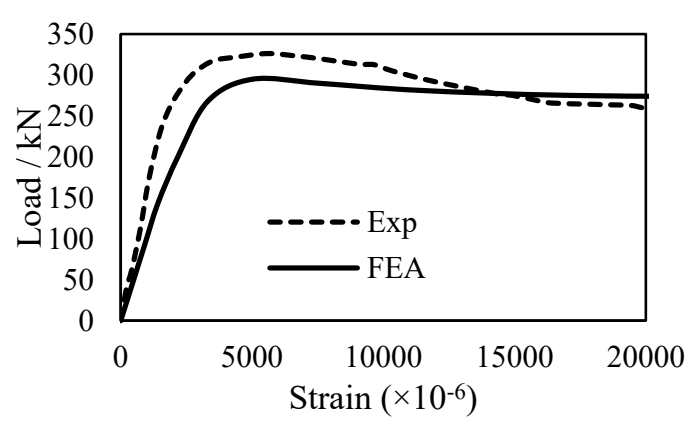

(d) CHS2-C100.

Fig. 2. Comparison of load-axial strain relationship of experimental and FE analysis.
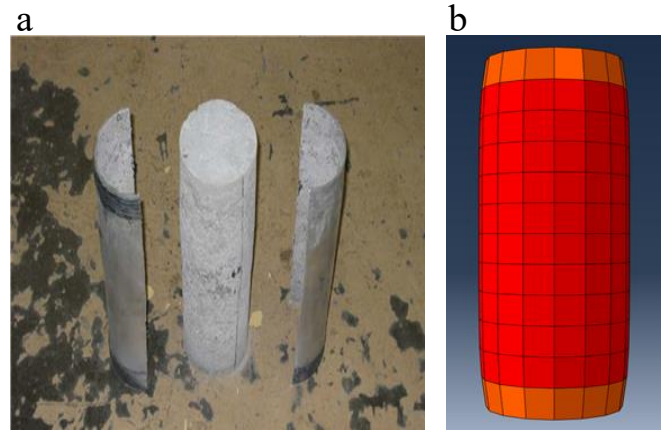

Fig. 3. Comparison of (a) experimental and (b) FE analysis failure modes.

\section{Analysis and discussion}

Behavioral analyses have been carried out by using one typical CFAT stub column reported by Zhou and Young [2]. The diameter and the thickness of the specimen were 50.0 $\mathrm{mm}$ and $3.13 \mathrm{~mm}$, respectively. The length of the tube was $150 \mathrm{~mm}$. The yield stress of aluminum tube and the mean value of concrete strength were 238.4 MPa and 106.0 MPa, respectively. Full histories of the corresponding load-deformation $N-\varepsilon$ response were studied.

Load-deformation $N-\varepsilon$ curves for CFAT stub columns are given in Fig. 4. The $N-\varepsilon$ responses of concrete and aluminum tube are also shown in Fig. 4. There are four characteristic points marked in the cure and the curves can be generally divided into four regions.

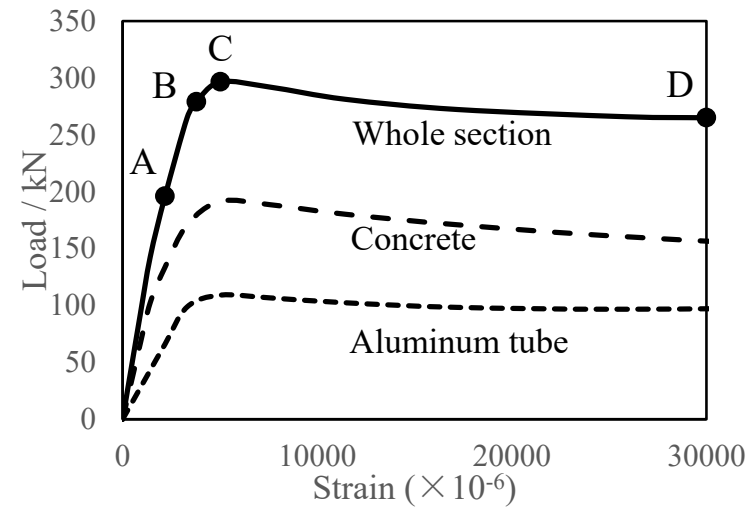

Fig. 4. Typical axial load versus axial deformation relation.

Stage 1: Elastic region (Points O-A). In this stage, the column remains elastic behavior. There is no evident interaction stress between aluminum tube and concrete. The load of aluminum tube and concrete are $32 \%$ and $68 \%$ of the ultimate strength of CFAT stub columns, respectively.

Stage 2: Elastic-plastic region (Points A-B). The confined concrete cracks and starts transverse deformation. The interaction stress between aluminum tube and concrete increases due to the increasing confinement effect. The aluminum tube yields at point B. The load of aluminum tube and concrete are $36 \%$ and $64 \%$ of the ultimate strength of CFAT stub columns, respectively.

Stage 3: Plastic region (Points B-C). During this stage, the aluminum stress exceeds its corresponding yield limits and the stress of concrete is higher than its cylinder strength due to the confinement of aluminum tube.

Stage 4: Softening or hardening region (CD). The longitudinal strain increases quickly in this stage. The maximum stress of core concrete is $19.8 \%$ larger than that of plain concrete since aluminum tube can provide confinement for CTAT stub columns.

\section{Parametric analysis}

Upon on validation of the FE models, the parametric analysis was carried out to investigate the influence of depth-to-thickness ratios, aluminum strengths and concrete strengths on the axial load versus the longitudinal strain. The measured material properties of the aluminum tubes and concrete tested by Zhou and Young [2] were used in the 
parametric analysis. The aluminum tubes were normal strength material (T5) and high strength material (T6) and the nominal concrete strengths were 40,70 and $100 \mathrm{MPa}$, respectively. The parametric study of the overall diameter-to-thickness $(D / t)$ ratio, which ranged from 10 to 160 , was also carried out.

\subsection{Strength effect of concrete}

The $N-\varepsilon$ curves of CFAT stub columns with different nominal strengths of concrete are presented in Fig. 5. A wide range of the concrete cylinder strengths of 40,70 and 100 $\mathrm{MPa}$ was studied. The aluminum tube without concrete infill was also investigated. It is shown that the ultimate strength and the stiffness increase as the concrete strength increases. The ultimate strength and the stiffness of the composite columns are much higher than those of the aluminum tubes are. This is due to the higher strength and stiffness of the concrete in the composite columns. However, it is also shown that the ductility decreases with the increase of the concrete strength.

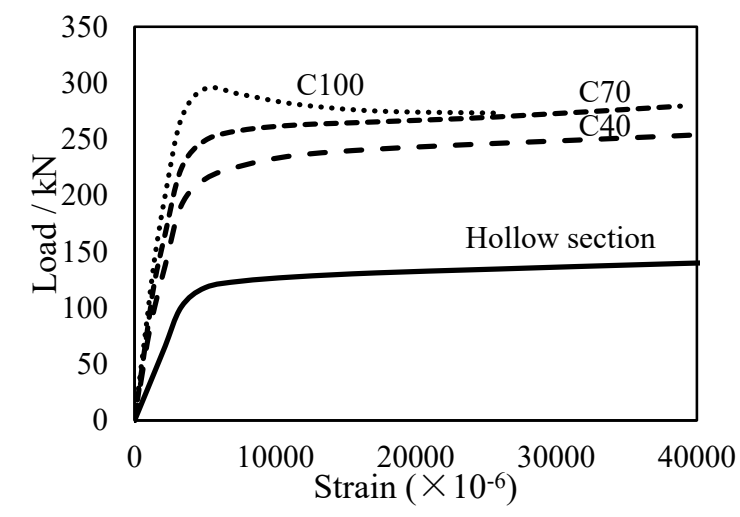

Fig. 5. Effect of concrete strength on axial load and longitudinal strain.

\subsection{Strength effect of aluminum tube}

The $N-\varepsilon$ curves of CFAT stub columns with different strengths of aluminum tubes are presented in Fig. 6. The normal strength aluminum tube has the yield stress of 185.9 $\mathrm{MPa}$ and the high strength aluminum tube has the yield stress of $267.9 \mathrm{MPa}$. It is shown that the ultimate strength increases as the strength of the aluminum tube increases. This is attributed to the higher confinement effect provided by the high strength aluminum. The influence of the strength on ductility is not obvious.

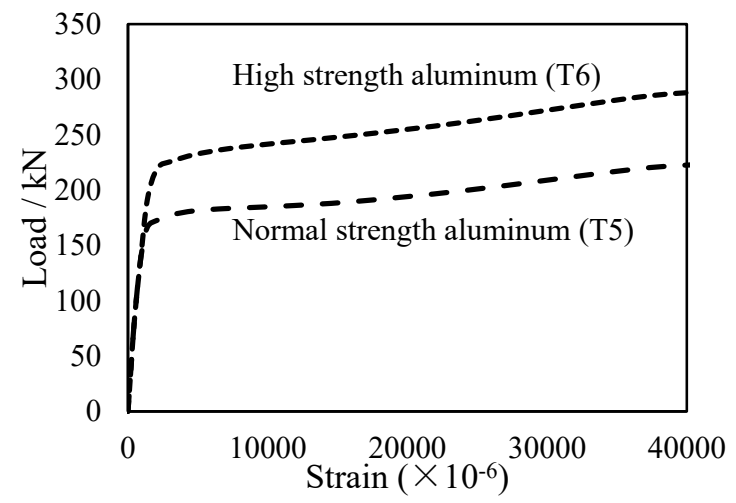

Fig. 6. Effect of aluminum tube strength on axial load and longitudinal strain.

\subsection{Effect of diameter-to-thickness ratio}

The $N-\varepsilon$ curves of CFAT stub columns with different diameter-to-thickness $(D / t)$ ratio are presented in Fig. 7. It is shown that the ultimate strength increases as the $D / t$ ratio decreases. This is attributed to that the area of steel tube is enlarged and yield stress of steel tube is higher than that of confined concrete. For specimens with $D / t$ less than 20.0, $N-\varepsilon$ curves are observed with no decline due to confinement effect provided by the aluminum tube, phenomenon of which is similar to that of concrete-filled steel tube [12].

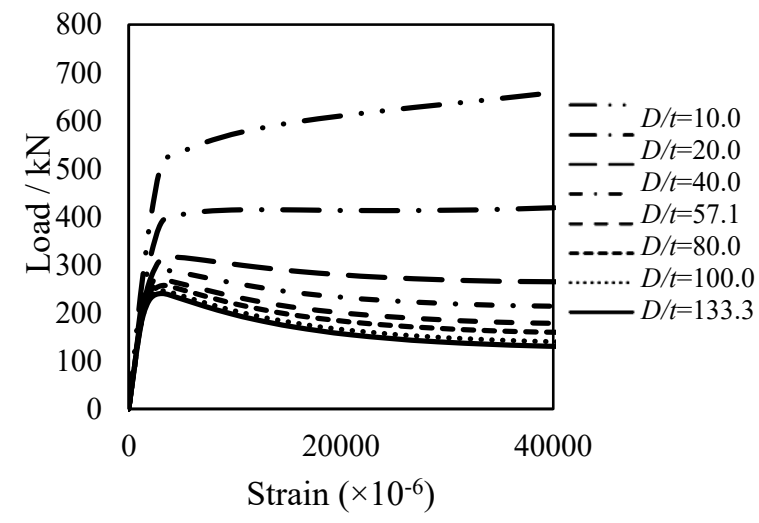

Fig. 7. Effect of depth-to-thickness ratio on axial load and longitudinal strain.

\section{Conclusions}

The following conclusions can be drawn:

1) FE models of CFAT stub columns under axial compression were developed using the FE package ABAQUS. The model consists of three main components: the aluminum tube, concrete infill and the interface between the aluminum tube and the concrete infill. It is shown that good agreements have been achieved 
between the experimental results and FE results in terms of the ultimate loads, the load-axial strain relationship and the failure modes.

2) Structural behavior of full histories of the load-deformation $N-\varepsilon$ response was discussed, where $N-\varepsilon$ curves were divided into four regions and each of them was analyzed accordingly.

3) Parametric studies were carried out to investigate the influences of depth-tothickness ratios, aluminum grades and concrete strengths on the structural behavior of the specimens. The ultimate strength increases as the increasing of the concrete strength or the yield stress of the aluminum tube. The ultimate strength and ductility increases as the $D / t$ ratio decreases due to the increase of the confinement provided by the aluminum tube.

4) This paper presents numerical investigation of circular concrete-filled aluminum tubular (CFAT) stub columns. CFAT stub columns using square and rectangular hollow sections still need to be investigated. Experimental and numerical results of circular, square and rectangular CFAT stub columns need further study to be compared with the design capacity predictions from existing international codes.

\section{References}

[1] Zhou F, Young B. Tests of concrete-filled aluminum stub columns. Thin-Walled Structures 2008; 46(6): 573-583.

[2] Zhou F, Young B. Concrete-filled aluminum circular hollow section column tests. ThinWalled Structures 2009; 47(11): 1272-1280.

[3] Chen Y, Feng R, Xu J. Flexural behaviour of CFRP strengthened concrete-filled aluminium alloy CHS tubes. Construction and Building Materials 2017; 142: 295-319.

[4] Feng R, Chen Y, Gong W. Flexural behaviour of concrete-filled aluminium alloy thin-walled SHS and RHS tubes. Engineering Structures 2017; 137: 33-49.
[5] Gardner L, Ashraf M. Structural design for nonlinear metallic materials. Engineering Structures 2006; 28(6): 926-934.

[6] Su M-N, Young B, Gardner L. Testing and Design of Aluminum Alloy Cross Sections in Compression. Journal of Structural Engineering 2014; 140(9): 4014047.

[7] Zhu J H, Young B. Tests and design of aluminum alloy compression members. Journal of Structural Engineering 2006; 132(7): 10961107.

[8] ABAQUS. ABAQUS Standard User's Manual, Version 6.14, Dassault Systemes Corp., Providence, RI (USA); 2014.

[9] Zhou F, Young B. Numerical analysis and design of concrete-filled aluminum circular hollow section columns. Thin-Walled Structures 2012; 50(1): 45-55.

[10]American Concrete Institute. Building Code Requirements for Structural Concrete (ACI 31811) and Commentary; 2011.

[11] Han LH, Yao GH, Tao Z. Performance of concrete-filled thin-walled steel tubes under pure torsion. Thin-Walled Structures 2007; 45(1): 24-36.

[12]Han LH. Concrete Filled Steel Tubular Structures - Theory and Practice (in Chinese). Third. China Science Publishing \& Media Ltd.; 2016.

[13]Hillerborg A, Modéer M, Petersson P-E. Analysis of crack formation and crack growth in concrete by means of fracture mechanics and finite elements. Cement and Concrete Research 1976; 6(6): 773-781. 